\title{
P-24
}

\section{Total Phenolic Compounds, Antioxidant, Anticancer and Antidiabetic Properties of Myrmecodia Tuberosa (Rubiaceae)}

\author{
Saidi Rasemi ${ }^{1}$, Khong Heng Yen ${ }^{1, *}$ and Rohaya Ahmad ${ }^{2}$ \\ ${ }^{1}$ Faculty of Applied Sciences, Universiti Teknologi MARA, 94300 Kota Samarahan, Sarawak, Malaysia; ${ }^{2}$ Faculty of \\ Applied Sciences, Universiti Teknologi MARA,40450 Shah Alam, Malaysia; E-mail: khonghy@sarawak.uitm.edu.my
}

Myrmecodia tuberosa or locally known as "Sarang Semut", belongs to Rubiaceae family. The aim of the study is to investigate the total phenolic compounds and bioactivity of the crude extract of M. tuberosa. The tuber, bark and leaves of the plant were cut, wash and air-dried. The plant was extracted with ethyl acetate and ethanol to yield EtOAc and EtOH crude. The crude were then tested for anti-oxidant 2,2-diphenyl-1-(2,4,6-trinitrophenyl)hydrazyl (DPPH) assay, $\alpha$-glucosidase assay for anti-diabetic activity, and MTT assay for cytotoxicity test. The results showed that bark ethanolic extract demonstrated the highest DPPH scavenging of $97.49 \%$ while other crudes were ranging from $95.04 \%$ to $96.86 \%$ scavenging of DPPH compared to ascorbic acid. An in-vitro $\alpha$ glucosidase assay was performed according to the slightly modified method of Matsui et al. (1996) showed that the tuber ethyl acetate extract demonstrated the highest inhibition of $\alpha$-glucosidase enzyme with $72.58 \%$ while other crudes were ranging from $63.27 \%$ to $72.46 \%$ inhibition. In addition, the ethanolic tuber extract exhibited the strongest cytotoxicity against HT-29 and Hela cell lines with the $\mathrm{IC}_{50}$ value of $16 \mu \mathrm{g} / \mathrm{mL}$ and $14 \mu \mathrm{g} / \mathrm{mL}$ respectively. Meanwhile, the ethanolic bark extract exhibited the strongest cytotoxicity against MCF-7 with $\mathrm{IC}_{50}$ value of $6.0 \mu \mathrm{g} / \mathrm{mL}$. The total phenolic content results also showed that the tuber extracts contained the highest phenolic content with $1087 \mathrm{mg} \mathrm{GAE} / \mathrm{g}$ extract compared to leaf and bark of the plants. The findings suggest that the whole part of M. tuberosa is a potential natural source for anti-oxidative, anti-diabetic and anti-cancer agent.

Keywords: Rubiaceae, Myrmecodia tuberosa, Antioxidant, Anticancer, Antidiabetic. 